\title{
Suppression of hesA mutation on nitrogenase activity in Paenibacillus polymyxa WLY78 with the addition of high levels of molybdate or cystine
}

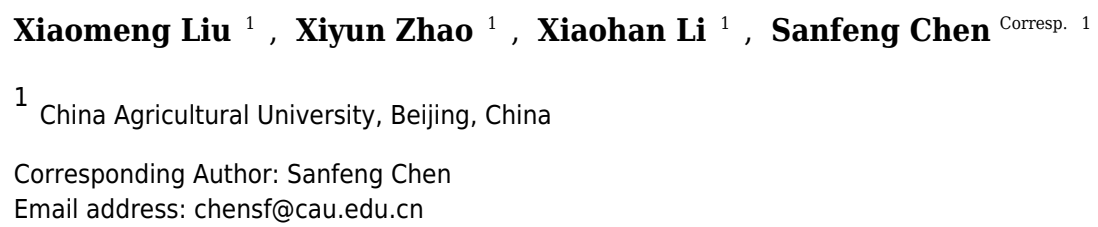

The diazotrophic Paenibacillus polymyxa WLY78 possesses a minimal nitrogen fixation gene cluster consisting of 9 genes (nifB nifH nifD nifK nifE nifN nifX hesA and nifV). Notably, the hesA gene contained within the nif gene cluster is also found within nif gene clusters among diazotrophic cyanobacteria and Frankia. The predicted product HesA is a member of the ThiF-MoeB-HesA family containing an N-terminal nucleotide binding domain and a C-terminal MoeZ/MoeB-like domain. However, the function of hesA gene in nitrogen fixation is unknown. In this study, we demonstrate that hesA mutation of $P$. polymyxa WLY78 leads to nearly complete loss of nitrogenase activity. The effect of the mutation can be partially suppressed by the addition of high levels of molybdate or cystine. However, the nitrogenase activity of the hesA mutant could not be restored by Klebsiella oxytoca nifQ or Escherichia coli moeB completely. In addition, the hesA mutation does not affect nitrate reductase activity of $P$. polymyxa WLY78. Our results demonstrate hesA is a novel gene specially required for nitrogen fixation and its role is related to introduction of $\mathrm{S}$ and Mo into the FeMo-co of nitrogenase. 
1

4

5

6

7 State Key Laboratory for Agrobiotechnology and Key laboratory of Soil Microbiology of

8 Agriculture Ministry, China Agricultural University, Beijing, 100193, P. R. China

9 * Correspondence: Sanfeng Chen

10

11

12

13

14

15

16

17

18

19

20

21

\section{molybdate or cystine}

Xiaomeng Liu, Xiyun Zhao, Xiaohan Li, Sanfeng Chen*
E-mail: chensf@cau.edu.cn

Tel.: +86-10-62731551
2 
24 Abstract

25 The diazotrophic Paenibacillus polymyxa WLY78 possesses a minimal nitrogen fixation gene cluster consisting of 9 genes (nifB nifH nifD nifK nifE nifN nifX hes $A$ and nifV). Notably, the hesA gene contained within the nif gene cluster is also found within nif gene clusters among diazotrophic cyanobacteria and Frankia. The predicted product HesA is a member of the ThiF-MoeB-HesA family containing an N-terminal nucleotide binding domain and a C-terminal MoeZ/MoeB-like domain. However, the function of hes $A$ gene in nitrogen fixation is unknown. In this study, we demonstrate that hesA mutation of $P$. polymyxa WLY78 leads to nearly complete loss of nitrogenase activity. The effect of the mutation can be partially suppressed by the addition of high levels of molybdate or cystine. However, the nitrogenase activity of the hes $A$ mutant could not be restored by Klebsiella oxytoca nifQ or Escherichia coli moeB completely. In addition, the hesA mutation does not affect nitrate reductase activity of $P$. polymyxa WLY78. Our results demonstrate hes $A$ is a novel gene specially required for nitrogen fixation and its role is related to introduction of S and Mo into the FeMo-co of nitrogenase. 


\section{Introduction}

46 Nitrogenase, nitrate reductase, and a number of other enzymes require molybdenum and sulfur

47 for their activity (Johnson 1980; Lester \& Demoss 1971; Pienkos et al. 1977; Shah et al. 1984).

Molybdenum and sulfur are found in these molybdoenzymes as parts of low-molecular-weight cofactors (Johnson 1980; Shah \& Brill 1980). Two different molybdenum cofactors have been described: iron-molybdenum cofactor (FeMo-co), which is found only in nitrogenase (Pienkos et al. 1977; Shah \& Brill 1980), and molybdenum cofactor (Mo-co), which is found in other molybdoenzymes.

Most biological nitrogen fixation is catalyzed by molybdenum-dependent nitrogenase, which is distributed within bacteria and archaea. This nitrogenase is a two-component enzyme consisting of the Fe and MoFe proteins (Hu \& Ribbe 2011; Rubio \& Ludden 2008). The MoFe protein is an $\alpha_{2} \beta_{2}$ heterotetramer (encoded by nifD and nifK) that contains two metalloclusters; FeMo-co, a [Mo7Fe-9S-C-homocitrate] cluster which serves as the active site of substrate binding and reduction and the P-cluster, a [8Fe-7S] cluster which shuttles electrons to FeMo-co. The Fe protein (encoded by $n i f H$ ) is a $\gamma_{2}$ homodimer bridged by an intersubunit [4Fe-4S] cluster that serves as the obligate genetic and biochemical analysis that nifE, nif $N$, nif $X$, nifB, nifQ, nifV, nif $Y$ and nifU, nifS and nifH contribute to the synthesis and insertion of FeMo-co into nitrogenase (Hu \& Ribbe 2011; Rubio \& Ludden 2008). Of these genes, nifQ serves as a molybdenum donor for FeMo-co synthesis, nif $U$ 
64 and nifS are involved in [Fe-S] cluster assembly. NifS is a cysteine desulfurase that provides sulfur

65 for the assembly of transient [Fe-S] clusters onto the molecular scaffold NifU.

66 Mo-co consists of the molybdopterin cofactor with molybdenum bound to its dithiolene moiety.

67 Mo-co is found in nitrate reductase of some fungi and bacteria, such as nitrate reductase of Escherichia coli (Leimkühler et al. 2011; Mendel 2013). In E. coli, several loci (moa, mob, moe, and $m o g$ ) are involved in the biosynthesis of the Mo-co (Leimkühler et al. 2001). In Mo-co biosynthesis, MoeB functions to sulfurylate MoaD, and IscS functions as a primary sulfurdonating enzyme by interacting specifically with MoeB and MoaD in the biosynthesis of molybdopterin in E. coli (Sambasivarao et al. 2002; Zhang et al. 2010).

Diazotrophic (nitrogen-fixing) Gram-positive and endospore-formed Paenibacillus spp. have potential uses as a bacterial fertilizer in agriculture. Comparative genomic analysis shows that a nif gene cluster composed of 9 genes nifBHDKENXhesAnifV is conserved in the genomes of $P$. polymyxa WLY78 and other the diazotrophic Paenibacillus species and strains. Whereas, the Gram-negative diazotrophic model Klebsiella oxytoca has 20 nif genes (nifJHDKTYENXUSVWZMFLABQ) organized in 7 transcriptional units and co-located within a $24 \mathrm{~kb}$ cluster (Arnold et al. 1988). Compared to K. oxytoca, P. polymyxa WLY78 has no nifQ, nifS and nif $U$, but contains a hes $A$ gene. The hesA gene is aslo highly conserved within the nif gene clusters of Cyanobacteria and Actinobacteria (Frankia). The predicted product HesA is a member of the ThiF-MoeB-HesA family containing an N-terminal nucleotide binding domain and a Cterminal MoeZ/MoeB-like domain. However, the function of hesA gene in nitrogen fixation is unknown. 
In this study, the function of the P. polymyxa hesA gene in nitrogen fixation is investigated. Mutation of $P$. polymyxa hesA leads to no $\mathrm{N}_{2}$-fixation in the media containing low levels of molybdate. The effect of the mutation can be suppressed by the addition of high levels of molybdate or cystine. The hesA mutation does not affect nitrate reductase activity of $P$. polymyxa WLY78. Our results demonstrate hesA is specially required for nitrogen fixation.

\section{Materials \& Methods}

\section{Bacterial strains and media}

Bacterial strains used in this study are listed in Table S1. P. polymyxa WLY78, mutants and the recombinant $E$. coli strains were grown in $\mathrm{LB}$ medium at $37^{\circ} \mathrm{C}$. When appropriate, antibiotics for E. coli strains and P. polymyxa WLY78 mutants were required. For $P$. polymyxa WLY78 mutant strains, antibiotics were added at $5 \mathrm{mg} / \mathrm{L}$ chloramphenicol, $12.5 \mathrm{mg} / \mathrm{L}$ tetracycline. While for $E$. coli, antibiotics were added at $100 \mathrm{mg} / \mathrm{L}$ ampicillin, $25 \mathrm{mg} / \mathrm{L}$ tetracycline and $25 \mathrm{mg} / \mathrm{L}$ chloramphenicol for maintenance of plasmids.

Nitrogen-limited medium (per liter contains: $10.4 \mathrm{~g} \mathrm{Na}_{2} \mathrm{HPO}_{4}, 3.4 \mathrm{~g} \mathrm{KH}_{2} \mathrm{PO}_{4}, 26 \mathrm{mg}$ $\mathrm{CaCl}_{2} \cdot 2 \mathrm{H}_{2} \mathrm{O}, 30 \mathrm{mg} \mathrm{MgSO}_{4}, 0.3 \mathrm{mg} \mathrm{MnSO}_{4}, 36 \mathrm{mg}$ Ferric citrate, $7.6 \mathrm{mg} \mathrm{Na} \mathrm{MoO}_{4} \cdot 2 \mathrm{H}_{2} \mathrm{O}, 10 \mu \mathrm{g}$ p-aminobenzoic acid, $10 \mu \mathrm{g}$ biotin, $4 \mathrm{~g}$ glucose as carbon source and $0.3 \mathrm{~g}$ glutamic acid as nitrogen source) was used for assay of nitrogenase activity (Wang et al. 2013). When necessary, different concentrations of $\mathrm{Na}_{2} \mathrm{MoO}_{4}$ or cystine or sulfate were supplemented in the nitrogen-limited medium.

To determine nitrate reductase activity, $P$. polymyxa WLY78 and mutant strains were cultured in mineral salts medium (per liter contains: $9.16 \mathrm{~g} \mathrm{~K}_{2} \mathrm{HPO}_{4} \cdot 3 \mathrm{H}_{2} \mathrm{O}, 1.0 \mathrm{~g}\left(\mathrm{NH}_{4}\right)_{2} \mathrm{SO}_{4}, 0.22 \mathrm{~g}$ 
106

107

108

109

110

111

112

113

114

115

116

117

118

119

120

121

122

123

124

125

126

$\mathrm{MgSO}_{4} \cdot 7 \mathrm{H}_{2} \mathrm{O}, 2.0 \mathrm{~g} \mathrm{KH}_{2} \mathrm{PO}_{4}, 8.0 \mathrm{~g}$ nutrient broth, $10 \mathrm{~g} \mathrm{KNO}$, 10 g glucose ) (Sperl \& Demoss 1975).

\section{Enzyme assays}

For nitrogenase activity assays, $P$. polymyxa WLY78, mutants, the complemented strains and the recombinant E. coli strains were grown in $20 \mathrm{ml}$ of LB media (supplemented with antibiotics) in $50 \mathrm{ml}$ flasks shaken at $200 \mathrm{rpm}$ overnight at $37^{\circ} \mathrm{C}$. The cultures were collected by centrifugation, precipitations were washed three times with sterilized water and then resuspended in nitrogenlimited medium containing different concentrations of $\mathrm{Na}_{2} \mathrm{MoO}_{4}$ (supplemented with antibiotics for mutants and the engineered $E$. coli strains when necessary) to a final $\mathrm{OD}_{600 \mathrm{~nm}}$ of $0.2-0.5$. The nitrogenase activity was determined by the procedure described by Xie et al (Xie et al. 2012).

For the assay of nitrate reductase, $P$. polymyxa WLY78 and mutant strains were grown in $50 \mathrm{ml}$ of LB media in $100 \mathrm{ml}$ flasks shaken at $200 \mathrm{rpm}$ for $16 \mathrm{~h}$ at $37^{\circ} \mathrm{C}$. The cultures were collected by centrifugation, washed three times with sterilized water and then resuspended in mineral salts medium. The cultures were grown at $200 \mathrm{rpm}$ at $37^{\circ} \mathrm{C}$ anaerobically. The nitrate reductase was determined by the method described by Garzón (Garzón et al. 1992). Nitrate reductase activity was expressed as nanomoles of nitrite $\cdot \operatorname{minute}^{-1} \cdot$ milligram $^{-1}$ of cell protein.

\section{Growth of the wild type and mutant strains}

To measure growth of strains cultured in different concentrations of $\mathrm{Na}_{2} \mathrm{MoO}_{4}$, cells were grown in $20 \mathrm{ml}$ of LB media in $50 \mathrm{ml}$ flasks shaken at $200 \mathrm{rpm}$ at $37^{\circ} \mathrm{C}$ overnight. The cultures were collected by centrifugation, washed three times with sterilized water and then resuspended in sufficient nitrogen medium (nitrogen-limited medium supplemented with $100 \mathrm{mM} \mathrm{NH}_{4} \mathrm{Cl}$ ) 
127 containing different concentrations of $\mathrm{Na}_{2} \mathrm{MoO}_{4}$ to a start $\mathrm{OD}_{600 \mathrm{~nm}}$ of 0.1 . After incubating the 128 cultures for $48 \mathrm{~h}$ at $37^{\circ} \mathrm{C}$ with shaking at $250 \mathrm{rpm}$, the maximum growth of $P$. polymyxa WLY78 129 and mutant strains were determined by absorbancy at $600 \mathrm{~nm}$.

\section{Construction of Paenibacillus hes $\boldsymbol{A}$ mutant strain}

The Paenibacillus hesA mutant was constructed through homologous recombination with pRN5101 (Hou et al. 2016), which carries a temperature-sensitive region from plasmid pE194ts (Villafane et al. 1987) containing two replication origins: one is pMB1 which can be reproduced in E. coli and the other replicon is from a plasmid pE194 which can be reproduced in Gram-positive Bacillus (Gryczan et al. 1978). A 3432 bp DNA fragment, including a 1119 bp upstream sequence and a 1116 bp downstream fragment of the hesA coding region, was cloned to pRN5101. Then, a 1197 bp DNA fragment, including the promoter and coding region of chloramphenicol $(\mathrm{Cm})$ resistant gene, was amplified from plasmid pPR9TT and inserted between upstream and downstream homologous arms in the opposite direction from the nif genes, generating plasmid pRN5101-Cm. The plasmid pRN5101-Cm was introduced into P. polymyxa WLY78 by electroporation (BTX, ECM 399) for homologous recombination. Transformants resistant to chloramphenicol were grown at $30^{\circ} \mathrm{C}$ and transferred to $5 \mathrm{ml}$ of LB media (supplemented with 5 $\mathrm{mg} / \mathrm{L}$ chloramphenicol) in $20 \mathrm{ml}$ test tubes shaken at $200 \mathrm{rpm}$ for $36 \mathrm{~h}$ at $39^{\circ} \mathrm{C}$ for about 5 generations. The strains were then plated onto LB agar plates supplemented with chloramphenicol and incubated for $24 \mathrm{~h}$ at $39^{\circ} \mathrm{C}$. Integration of the recombinant plasmid was confirmed by PCR and sequencing. The deletion mutant strain was designated as $\Delta h e s A$. 
WLY78, K. oxytoca M5a1 and E. coli K12, respectively. These PCR products, being under the control of nifB promoter of $P$. polymyxa WLY78, were cloned to the plasmid pHY300PLK, respectively. Then the recombinant plasmids were introduced into $P$. polymyxa hes $A$ mutant, respectively.

For complementation of the hes $A$ deletion of the recombinant E. coli 78-7 which carries a nif gene cluster composed of 9 genes (nifBHDKENXhesAnifV) from $P$. polymyxa WLY78 (Wang et al. 2013), the $P$. polymyxa hes $A$ coding region, being under the control of nifB promoter of $P$. polymyxa WLY78 was cloned to vector pBluescript II SK(+) that contained a chloramphenicol expression cassette, producing the recombinant plasmid pBluescript II SK (+)-hesA. Primers for

PCR are listed in Table S2. Recombinant plasmids and strains are listed in Table S3.

\section{Quantitative real-time PCR (qRT-PCR) analysis of nif $V$ expression}

For qRT-PCR, cultures of $P$. polymyxa WLY78 and $\Delta$ hes $A$ were grown in $\mathrm{N}_{2}$-fixing conditions

( $2 \mathrm{mM}$ glutamate and without $\mathrm{O}_{2}$ ) and harvested after $20 \mathrm{~h}$ of incubation. Total RNA was isolated using TRIzol (Takara Bio, cat. no. 9108) (Rio et al. 2010). The possibility of contamination of genomic DNA was eliminated by digestion with RNase-free DNase I (Takara Bio, cat. no. RR047A). The integrity and size distribution of the RNA were verified by agarose gel electrophoresis, and the concentrations were determined spectrophotometrically. Synthesis of cDNA was carried out using RT Prime Mix according to the manufacturer's specifications (Takara Bio, cat. no. RR047A). $0.4 \mu \mathrm{g}$ of cDNA was used for qRT-PCR. The relative transcript levels of nifV were determined with 16S rDNA as a control by SYBR Premix Ex Taq (Tli RNaseH Plus) 
169 kit (Takara Bio, cat. no. RR820A). Primers for nifV and 16S rDNA used for qRT-PCR are listed 170 in Table S2.

171 Statistical analysis

172 Statistical analyses were performed using SPSS 20.0 (SPSS, Chicago, IL, USA). The least 173 significant test (LSD) was calculated at the 0.05 or 0.01 probability level for different treatment mean comparisons of nitrogenase activity.

Results

A hes $A$ gene is highly conserved in nif gene clusters among diazotrophic Paenibacillus, cyanobacteria and Frankia

P. polymyxa WLY78 possesses a minimal nitrogen fixation (nif) gene cluster consisting of 9 genes (nifB nifH nifD nifK nifE nifN nifX hesA and nifV). Our previous results demonstrated that the recombinant $E$. coli $78-7$ which was generated by introducing the $P$. polymyxa nif gene cluster into E. coli JM109 could produce active nitrogenase (Wang et al. 2013). Notably, a hesA gene is contained within the nif gene cluster, and its predicted product HesA is a member of the ThiF-

MoeB-HesA family containing an N-terminal nucleotide binding domain and a C-terminal

MoeZ/MoeB-like domain. NCBI blast analyses reveal that hes $A$ gene is significantly conserved within nif gene clusters among diazotrophic Paenibacillus, cyanobacteria and Frankia (Fig. 1). HesA from $P$. polymyxa WLY78 at amino acid sequence level shares more than $90 \%$ identity with those of other diazotrophic Paenibacillus spp. (Xie et al. 2014) and 46.8\%, 43.1\% and 49.2\% identity with HesA of Frankia alni ACN14a (Chang et al. 2012), Cyanothece sp. ATCC 51142

(Welsh et al. 2008) and Anabaena sp. PCC 7120 (Mitschke et al. 2011), respectively. 
190

191

192

193

194

195

196

197

198

199

200

201

202

203

204

205

206

207

208

209

210

Furthermore, we find that $P$. polymyxa HesA has $32 \%, 30 \%, 26 \%$ and $24 \%$ identity with MoeB

of Pseudomonas fluorescens, K. oxytoca, E. coli and Bacillus subtilis, respectively, whereas it shows only $9 \%$ identities with NifQ of $K$. oxytoca and $A$. vinelandii and $8-18 \%$ with these NifQs from other $\mathrm{N}_{2}$-fixing bacteria. The data indicate that HesA exhibits higher similarity to MoeB than to NifQ. Also, there are no moeB-like genes other than hesA in Paenibacillus.

The hes $A$ mutation of $P$. polymyxa WLY78 leads to nearly complete loss of nitrogenase activity

As described in Materials and methods, the $\Delta$ hes $A$ mutant was constructed by inserting a 1197 bp chloramphenicol resistance gene cassette into the nif gene cluster (nifBHDKENXhesAnifV) and substituting for hesA. qRT-PCR further revealed that the mRNA level of nif $V$ gene was not affected by the hes $A$ mutation (Fig. S1), suggesting that the insertion of $\mathrm{Cm}$-cassette into nif gene cluster did not generate polarity effect.

Here, the nitrogenase activities of the $\Delta$ hes $A$ mutant and wild-type $P$. polymyxa WLY78 grown in medium containing $0.25 \mathrm{mM}$ sulfate as sulfur source and supplemented with $0.3 \mu \mathrm{M}$ and $30 \mu \mathrm{M}$ molybdate, respectively, were comparely analyzed (Fig. 2). The $\Delta$ hes $A$ mutant showed a significant decrease in nitrogenase activity compared to wild type, suggesting that hes $A$ is involved in nitrogen fixation. We noticed that the hesA mutant and $P$. polymyxa WLY78 also exibited some activity in medium without molybdate, which might be due to trace molybdenum in the medium.

Furthermore, we demonstrated that $P$. polymyxa hes $A$ could completely restore the activity of hesA mutant to the level of wild-type Paenibacillus, confirming that hesA is required for nitrogen fixation. We also tried to complement with $K$. oxytoca nifQ and found that the nifQ could not 
211 suppress the effect of hesA mutation completely (Fig. 2). The data suggest that K. oxytoca nifQ

212 could not act as a molybdenum donor for FeMo-co synthesis of nitrogenase in P. polymyxa.

213 The hes $A$ mutant requires high levels of molybdate for nitrogenase activity

214 The molybdate requirement for nitrogenase activity in the $\Delta$ hes $A$ mutant was studied, with $P$.

215 polymyxa WLY78 as a control. As shown in Fig. 3A, P. polymyxa WLY78 had nitrogenase activity

216 even in the absence of added sodium molybdate, because there were always traces of Mo in other

217 chemicals, the glassware and water. The maximum activity of wild-type $P$. polymyxa WLY78 was

218 obtained at $0.3 \mu \mathrm{M}$ molybdate, and the nitrogenase activity did not increase as the concentration

219 of molybdate increased. In contrast, the nitrogenase activity of the $\Delta h e s A$ mutant improved as the

220 molybdate concentration increased, and the maximum activity was obtained at $30 \mathrm{mM}$ molybdate.

221 The maximum activity of the $\Delta$ hes $A$ mutant at $30 \mathrm{mM}$ molybdate was $25 \%$ of that of the wild type

222 obtained at $0.3 \mu \mathrm{M}$ molybdate, indicating that the addition of very high levels of molybdate could

223 partially suppress the effect of the mutation.

224 Diazotrophic growth of the wild-type P. polymyxa WLY78 and $\Delta$ hes $A$ mutant showed the same

225 dependence on the molybdate added (Fig. 3B). Compared with the wild type, the $\Delta$ hes $A$ mutant

226 needed higher concentration of molybdate for the maximum growth. Millimolar concentrations of

227 molybdate obviously inhibited both activity and diazotrophic growth. Meanwhile, the $\Delta h e s A$

228 mutant showed a higher tolerance.

\section{Effect of two sulfur sources on nitrogenase activity of the $\Delta h e s A$ mutant}

230 Here, the effects of two sulfur sources on nitrogenase activity of the $\Delta$ hes $A$ mutant were 
232

233

234

235

236

237

238

239

240

241

242

243

244

245

246

247

248

249

250

251

252

containing cystine as the only sulfur source was 2 to 5 times higher than that in medium containing sulfate at all of different concentrations of molybdenum except for a high inhibitory level of 0.3

M molybdenum. However, no difference in nitrogenase activity of wild-type Paenibacillus was observed when using either sulfate or cystine as sulfur source (Fig. 4B). These results demonstrated that the use of cystine as the only sulfur source could suppress the effect of hesA mutation on nitrogenase activity, but the addition of cystine could not affect the requirement of molybdenum for maximum nitrogenase activity. The results indicated that hes $A$ might be involved in sulfur transport.

\section{High levels of cystine restore the nitrogenase activity of the $\Delta$ hes $A$ mutant, but $E$. coli moeB}

\section{can not}

As shown in Fig. 5A, the nitrogenase activity of the $\Delta$ hesA mutant was improved with the addition of cystine, and higher concentration of cystine was required for the $\Delta$ hes $A$ mutant to reach the maximum activity of the wild type. Similarly, the activity of the $\Delta h e s A$ mutant increased with the addition of sulfate, but higher concentration (above $1.0 \mathrm{mM}$ ) of sulfate was required for the $\triangle h e s A$ mutant to reach the maximum activity of the wild type (Fig. 5B).

In addition, we tried to complement the $\Delta$ hesA mutant with $E$. coli moeB and found that the expression of $m o e B$ in the mutant did not improve nitrogenase activity (Fig. 5). In fact, the nitrogenase activity in the $\Delta h e s A$ mutant expressing moeB declined when the concentration of cystine exceeded $1.0 \mathrm{mM}$. The data suggested that $E$. coli moeB could not completely suppress the effect of the hesA mutation when sulfate or cystine was used as the only sulfur source. It has been reported that MoeB, MPT synthase sulfurase, is involved in sulfuration of MPT synthase 
253 (Leimkühler et al. 2001; Pitterle \& Rajagopalan 1993; Rajagopalan 1997).

254 A high level of molybdate is reqiured for nitrogenase activity of the recombinant $E$. coli 78-

255

256

257

258

259

260

261

262

263

264

265

266

267

268

269

270

271

272

273

\section{7 with a hes $A$ deletion}

In order to confirm the role of the hes $A$ in nitrogen fixation, we compared the activities of the recombinant $E$. coli 78-7 strain carrying a nif gene cluster (nifBHDKENXhesAnifV) of P. polymyxa WLY78 (Wang et al. 2013) and the hesA deletion strain (D-O), which was a derivative of E. coli 78-7 strain without the hesA gene. As shown in Fig. 6, the nitrogenase activity of the D-O strain was improved as the concentration of molybdate increased. The D-O strain required 10 times as much molybdate to achieve the level of activity of the E. coli 78-7 strain. The P. polymyxa hes $A$ gene could complement the D-O strain and restore the activity of the hes $A$ deletion strain to that of the E. coli 78-7 strain, suggesting that the addition of very high levels of molybdate can suppress the effect of the hesA mutation. The current result was consistent with the results obtained in the P. polymyxa hesA mutant.

\section{Cystine can enhance activity of the hes $A$ deletion in $E$. coli 78-7}

Here, we further investigated the effect of cystine on the activities of the hes $A$ deletion strain (DO) which carried other nif genes (nifBHDKENXV) without hesA when it was grown in medium supplemented with $30 \mu \mathrm{M}$ molybdate and with different concentrations of cystine. As shown in Fig. 7, cystine could enhance activity of the hesA deletion strain (D-O), but it did not have the similar effects on the complemented strain D-O (pBluescript II SK (+)-hesA).

\section{The $P$. polymyxa hes $A$ mutation does not affect nitrate reductase activity}

Nitrate reductase, like nitrogenase, has been characterized as a molybdoenzyme (Taniguchi \& 
274 Itagaki 1960) and molybdenum is necessary for nitrate reductase (Lester \& Demoss 1971). Here,

275 the nitrate reductase activities of the $\Delta$ hes $A$ mutant and wild-type $P$. polymyxa WLY78 were

276 comparatively analyzed. The $\Delta$ hes $A$ mutant $\left(1048.12 \pm 28.80 \mathrm{nmol}\right.$ nitrite $\left.\cdot \mathrm{min}^{-1} \cdot \mathrm{mg}^{-1} \mathrm{protein}\right)$ and

277 wild-type $P$. polymyxa WLY78 (1057.37 $\pm 5.95 \mathrm{nmol}$ nitrite $\cdot \mathrm{min}^{-1} \cdot \mathrm{mg}^{-1}$ protein $)$ showed the

278 similar nitrate reductase activity, indicating that the hes $A$ gene product is required for synthesis of

279 FeMo-co, but not implicated in the biosynthesis of Mo-co.

280 Discussion

281 A nif gene cluster composed of 9 genes nifBHDKENXhesAnifV is conserved in the genomes of

282 P. polymyxa WLY78 and other the diazotrophic Paenibacillus spp. We find that the nif gene cluster

283 has a hesA, but no nifQ and nifSU. The genome of $P$. polymyxa WLY78 has molybdate transport

284 genes, including $\bmod A, \bmod C$ and $\bmod F$. It also contains moaA, moaB, moaC, moaD, moaE,

$285 m o b A, m o b B$ and moeA except for moeB, and contains a complete suf(sufCBSUD) operon, a partial

286 suf (sufABC) operon, a partial isc system (iscSR and $f d x$ ) and two nifS-like genes (Shi et al. 2016).

287 The function of hesA gene of diazotrophic Paenibacillus is here for the first time to be

288 investigated. Mutation of $P$. polymyxa hes $A$ leads to nearly complete loss of nitrogenase activity.

289 Similar result was reported that loss of hes $A$ resulted in about a $50 \%$ loss of nitrogenase in

290 Anabaena (Borthakur et al. 1990). Furthermore, we demonstrated that the effect of the mutation

291 could be suppressed by the addition of high levels of molybdate to the medium. We also showed

292 that deletion of hes $A$ from the nif gene cluster made the recombinant E. coli 78-7 require high

293 concentration of molybdate for nitrogenase activity. Our complementation studies demonstrated

294 that $P$. polymyxa hes $A$ could restore the nitrogenase activity of hes $A$ mutant to that of wild-type 
295

296

297

298

299

300

301

302

303

304

305

306

307

308

309

310

311

312

313

Paenibacillus or that of the recombinant E. coli 78-7, but $K$. oxytoca nifQ could not, indicating that $K$. oxytoca NifQ can not replace HesA in the original host. The results indicate that $P$. polymyxa hes $A$ gene plays a role in molybdenum transport to nitrogenase. Similar results that NifQand $\mathrm{Mol}^{-}$mutants of $K$. oxytoca required high concentration of molybdate for nitrogenase activity were reported (Imperial et al. 1984; Imperial et al. 1985). There were no functional differences among the NifQ- and $\mathrm{Mol}^{-}$mutants of $K$. oxytoca with respect to FeMo protein when molybdate was in excess (Imperial et al. 1985). Our results and their results suggest that NifQ is not necessary when molybdate is in excess. It was reported that the FeMo-co of nitrogenase could be completely synthesized in vitro by $\mathrm{Fe}^{2+}, \mathrm{S}^{2-}, \mathrm{MoO}_{4}{ }^{2-}$ and $R$-homocitrate, using purified NifB, NifEN and NifH proteins (Curatti et al. 2007). Curatti et al' s reports suggested that NifQ is not necessary when molybdate is in excess in vitro synthesis of FeMo-co. One possible explanation is that NifQ cannot act as Mo donor in Paenibacillus.

Sulfur is an essential element for FeMo-co of nitrogenase and Mo-co of other enzymes and it can be obtained from various compounds. Generally, sulfate $\left(\mathrm{SO}_{4}{ }^{2-}\right)$ and thiosulfate $\left(\mathrm{S}_{2} \mathrm{O}_{3}{ }^{2-}\right)$ are the preferred sulfur sources for the majority of $\mathrm{N}_{2}$-fixing organisms (Aguilar-Barajas et al. 2011). It was shown that the physiological sulfur donor for the formation of the dithiolene group of molybdopterin in Mo-co biosynthesis was likely to be $L$-cysteine and IscS functioned as a primary sulfur-donating enzyme by interacting specifically with MoeB and MoaD in the biosynthesis of molybdopterin in Escherichia coli (Sambasivarao et al. 2002; Zhang et al. 2010). MoeB contains 
314 several conserved cysteine residues, one of which has been postulated to be involved in the 315 formation of a thioester linkage between MoaD and MoeB (Rogers et al. 1995).

316 In this study, we demonstrated that cystine did not modify the requirement of molybdate for

317 nitrogenase activity in the wild-type $P$. polymyxa WLY78. Whereas, the nitrogenase activity of 318 the $\Delta$ hes $A$ mutant was higher when it was grown in medium containing cystine as the only sulfur 319 source than sulfate as the only sulfur source. Moreover, cystine could enhance activity of hes $A$ deletion of E. coli 78-7. However, P. polymyxa hes $A$ gene could not complement the hes $A$ deletion of $E$. coli 78-7 when cystine was high in the medium. We do not know whether E. coli moeB plays a role in nitrogen fixation of the hes $A$ mutant from the recombinant $E$. coli 78-7. It was reported that the effects of nifQ and mol mutations of $K$. oxytoca on nitrogenase could be suppressed by the addition of cystine, suggesting that a sulfur donor and molybdenum interact at an early step in the biosynthesis of the iron-molybdenum cofactor (Dos Santos \& Dean 2008). Sulfate interferes with the utilization of molybdate, which becomes apparently only when the nifQ or mol products are not active in K. oxytoca (Dos Santos \& Dean 2008). A competition between sulfate and molybdate was found in Clostridium pasteurianum (Elliott \& Mortenson 1975) and Aspergillus niger

329 (Tweedie \& Segel 1970) at the level of transport into the cell. The transport of sulfate and molybdate in $K$. oxytoca are independent and specific, and that the sulfur source effect on molybdate requirement is intracellular.

Furthermore, we comparatively analyzed the nitrate reductase activity of the $\Delta$ hes $A$ mutant and 333 wild-type P. polymyxa WLY78, and our results showed that the hesA mutation did not affect nitrate 
334 reductase activity. The results confirm that the $P$. polymyxa hes $A$ is involved in FeMo-co synthesis,

335 but not in Mo-co synthesis.

336

337

338

339

340

341 Acknowledgments

342 We would like to thank associate professor Yanqin Ding from Shandong Agricultural University

343 for gifting the plasmid pRN5101.

344

345

346

347

348

349

350

351

352

353

354 


\section{Figure captions}

364

365

366

367

368

369

370

371

372

373

374 375

Figure 1: Clusters of nitrogen-fixation related genes between $P$. polymyxa WLY78 and other nitrogen-fixing bacteria. (A) P. polymyxa WLY78, (B) Frankia sp. EAN1pec, (C) Cyanothece sp. ATCC 51142, (D) Anabaena sp. PCC 7120.

Figure 2: Relative nitrogenase activity of $P$. polymyxa WLY78, the $\Delta$ hesA mutant, the complemented strains $\Delta$ hesA (pHY300PLK-hesA) and $\Delta$ hesA (pHY300PLK-nifQ). X-axis indicates the concentration of molybdate added to the culture medium with $0.25 \mathrm{mM}$ sulfate as sulfur source. The nitrogenase activity of the $\Delta$ hes $A$ mutant was used as a control. Date represent the mean $\pm \operatorname{SD}(n=3)$. Single asterisk or double asterisks (* or **) indicate significant differences between control and other treatments determined by LSD at $P<0.05$ or $P<0.01$.

Figure 3: Effect of the molybdate concentration on nitrogenase activity (A) and maximum growth (B) of $P$. polymyxa WLY78 and the $\Delta$ hes $A$ mutant. X-axis indicates the concentration of molybdate added to the culture medium with $0.25 \mathrm{mM}$ sulfate as sulfur source. The maximum growth means 
376

377 of the $\Delta$ hesA mutant in the absence of added sodium molybdate was used as a control. Date

378 represent the mean $\pm \mathrm{SD}(\mathrm{n}=3)$. Single asterisk or double asterisks $(*$ or $* *)$ indicate significant

379 differences between control and other treatments determined by LSD at $P<0.05$ or $P<0.01$.

380

381

382

383

384

385

386

387

388

389

390

391

392

393

394

395

396

culture absorbance after 48 hours under diazotrophic growth conditions. The nitrogenase activity

Figure 4: Effect of the sulfur sources on the nitrogenase activity of the $\Delta h e s A$ mutant and $P$.

polymyxa WLY78. (A) Nitrogenase activity of $\Delta$ hes $A$ with two sulfur sources. (B) Nitrogenase

activity of $P$. polymyxa WLY78 with two sulfur sources. X-axis indicates the concentration of molybdate added to the culture medium with $0.25 \mathrm{mM}$ sulfate or $0.2 \mathrm{mM}$ cystine or the combination of sulfate and cystine as sulfur source. Date represent the mean \pm SD $(n=3)$. Single asterisk or double asterisks (* or $* *$ ) indicate significant differences among different treatments determined by LSD at $P<0.05$ or $P<0.01$.

Figure 5: Effect of the different concentrations of cystine (A) or sulfate (B) on nitrogenase activity of $\Delta$ hesA, P. polymyxa WLY78 and the complemented strain $\Delta$ hesA (pHY300PLK-moeB). (A)

Nitrogenase activity of the strains with different cystine concentrations. (B) Nitrogenase activity of the strains with different sulfate concentrations. X-axis indicates the concentration of cystine or sulfate added to the culture medium with $30 \mathrm{mM}$ molybdate. The nitrogenase activity of the $\Delta$ hes $A$ mutant was used as a control. Date represent the mean \pm SD (n=3). Single asterisk or double asterisks $(*$ or $* *)$ indicate significant differences between control and other treatments determined by LSD at $P<0.05$ or $P<0.01$.

Figure 6: Effect of the molybdate concentration on nitrogenase activity of the recombinant $E$. coli 78-7, the hes $A$ deletion strain (D-O) and the complemented strain D-O (pBluescript II SK (+)- 
397

398

399

400

401

402

403

404

405

406

407

408

409

410

411

412

413

414

415

416

417

hesA). X-axis indicates the concentration of molybdate added to the culture medium with $0.25 \mathrm{mM}$ sulfate as sulfur source. The nitrogenase activity of the D-O strain was used as a control. Date represent the mean $\pm \mathrm{SD}(\mathrm{n}=3)$. Single asterisk or double asterisks $(*$ or $* *)$ indicate significant differences between control and other treatments determined by LSD at $P<0.05$ or $P<0.01$.

Figure 7: Effect of the cystine concentration on nitrogenase activity of the recombinant $E$. coli 78-

7, the hes $A$ deletion strain (D-O) and the complemented strain D-O (pBluescript II SK (+)-hesA).

$\mathrm{X}$-axis indicates the concentration of cystine added to the culture medium with $30 \mu \mathrm{M}$ molybdate.

The nitrogenase activity of the D-O strain was used as a control. Date represent the mean $\pm \mathrm{SD}$

$(\mathrm{n}=3)$. Single asterisk or double asterisks $(*$ or $* *)$ indicate significant differences between control and other treatments determined by LSD at $P<0.05$ or $P<0.01$.

Figure S1: The relative transcript levels of nif $V$ were determined by qRT-PCR. The transcript level of nif $V$ of the wild-type $P$. polymyxa WLY78 was used as a control. Data represent the mean \pm SD of three independent experiments performed in triplicate.

\section{Table captions}

Table S1: Strains used in this study.

Table S2: Sequences of the primers used in this study.

Table S3: Plasmids used in this study. 


\section{References}

Aguilar-Barajas E, Díaz-Pérez C, Ramírez-Díaz MI, Riveros-Rosas H, and Cervantes C. 2011. Bacterial transport of sulfate, molybdate, and related oxyanions. BioMetals 24:687707 DOI 10.1007/s10534-011-9421-x.

Arnold W, Rump A, Klipp W, Priefer UB, and Puhler A. 1988. Nucleotide sequence of a 24,206-base-pair DNA fragment carrying the entire nitrogen fixation gene cluster of Klebsiella pneumoniae. Journal of Molecular Biology 203:715-738.

Borthakur D, Basche M, Buikema WJ, Borthakur PB, and Haselkorn R. 1990. Expression, nucleotide sequence and mutational analysis of two open reading frames in the nif gene region of Anabaena sp. strain PCC7120. Molecular and General Genetics 221:227-234.

Chang JO, Kim HB, Kim J, Kim WJ, Lee H, and An CS. 2012. Organization of nif gene cluster in Frankia sp. EuIK1 strain, a symbiont of Elaeagnus umbellata. Archives of Microbiology 194:29-34 DOI 10.1007/s00203-011-0732-7.

Curatti L, Hernandez JA, Igarashi RY, Soboh B, Zhao D, and Rubio LM. 2007. In vitro synthesis of the iron-molybdenum cofactor of nitrogenase from iron, sulfur, molybdenum, and homocitrate using purified proteins. Proceedings of the National Academy of Sciences of the United States of America 104:17626-17631 DOI 10.1073/pnas.0703050104.

Dos Santos PC, and Dean DR. 2008. A newly discovered role for iron-sulfur clusters. Proceedings of the National Academy of Sciences of the United States of America 105:11589-11590 DOI 10.1073/pnas.0805713105.

Elliott BB, and Mortenson LE. 1975. Transport of molybdate by Clostridium pasteurianum. Journal of Bacteriology 124:1295-1301.

Garzón A, Li J, Flores A, Casadesus J, and Stewart V. 1992. Molybdenum cofactor (chlorateresistant) mutants of Klebsiella pneumoniae M5al can use hypoxanthine as the sole nitrogen source. Journal of Bacteriology 174:6298-6302.

Gryczan TJ, Contente S, and Dubnau D. 1978. Characterization of Staphylococcus aureus plasmids introduced by transformation into Bacillus subtilis. Journal of Bacteriology 134:318-329.

Hou XY, Yu XN, Du BH, Liu K, Yao LT, Zhang SC, Selin C, Fernando WG, Wang CQ, and Ding YQ. 2016. A single amino acid mutation in Spo0A results in sporulation 
deficiency of Paenibacillus polymyxa SC2. Research in Microbiology 167:472-479 DOI 10.1016/j.resmic.2016.05.002.

Hu Y, and Ribbe MW. 2011. Biosynthesis of nitrogenase FeMoco. Coordination Chemistry Reviews 255:1218-1224 DOI 10.1016/j.ccr.2010.11.018.

Imperial J, Ugalde RA, Shah VK, and Brill WJ. 1984. Role of the nif $Q$ gene product in the incorporation of molybdenum into nitrogenase in Klebsiella-pneumoniae. Journal of Bacteriology 158:187-194.

Imperial J, Ugalde RA, Shah VK, and Brill WJ. 1985. Mol- mutants of Klebsiella pneumoniae requiring high levels of molybdate for nitrogenase activity. Journal of Bacteriology 163:1285-1287.

Johnson JL. 1980. The molybdenum cofactor common to nitrate reductase, xanthine dehydrogenase and sulfite oxidase: Pergamon Press.

Leimkühler S, Wuebbens MM, and Rajagopalan KV. 2011. The history of the discovery of the molybdenum cofactor and novel aspects of its biosynthesis in bacteria. Coordination Chemistry Reviews 255:1129-1144 DOI 10.1016/j.ccr. 2010.12.003.

Leimkühler S, Wuebbens MM, and Rajagopalan KV. 2001. Characterization of Escherichia coli MoeB and its involvement in the activation of molybdopterin synthase for the biosynthesis of the molybdenum cofactor. Journal of Biological Chemistry 276:3469534701 .

Lester RL, and Demoss JA. 1971. Effects of molybdate and selenite on formate and nitrate metabolism in Escherichia coli. Journal of Bacteriology 105:1006.

Mendel RR. 2013. The molybdenum cofactor. Journal of Biological Chemistry 288:1316513172 DOI 10.1074/jbc.R113.455311.

Mitschke J, Vioque A, Haas F, Hess WR, and Muro-Pastor AM. 2011. Dynamics of transcriptional start site selection during nitrogen stress-induced cell differentiation in Anabaena sp. PCC7120. Proceedings of the National Academy of Sciences of the United States of America 108:20130-20135 DOI 10.1073/pnas.1112724108.

Oldroyd GE, and Dixon R. 2014. Biotechnological solutions to the nitrogen problem. Current Opinion in Biotechnology 26:19-24 DOI 10.1016/j.copbio.2013.08.006.

Pienkos PT, Shah VK, and Brill WJ. 1977. Molybdenum cofactors from molybdoenzymes and in vitro reconstitution of nitrogenase and nitrate reductase. Proceedings of the National Academy of Sciences of the United States of America 74:5468-5471.

Pitterle DM, and Rajagopalan KV. 1993. The biosynthesis of molybdopterin in Escherichia coli. Purification and characterization of the converting factor. Journal of Biological Chemistry 268:13499.

Rajagopalan KV. 1997. Biosynthesis and processing of the molybdenum cofactors. Biochemical Society Transactions 25:757-761.

Rio DC, Jr AM, Hannon GJ, and Nilsen TW. 2010. Purification of RNA using TRIzol (TRI reagent). Cold Spring Harbor Protocols 2010:pdb.prot5439.

Rogers KC, Crescenzo AT, and Söll D. 1995. Aminoacylation of transfer RNAs with 2thiouridine derivatives in the wobble position of the anticodon. Biochimie 77:66-74. 
494

495

Rubio LM, and Ludden PW. 2008. Biosynthesis of the iron-molybdenum cofactor of nitrogenase. Annual Review of Microbiology 62:93-111 DOI 10.1146/annurev.micro.62.081307.162737.

Sambasivarao D, Turner RJ, Bilous PT, Rothery RA, Shaw G, and Weiner JH. 2002. Differential effects of a molybdopterin synthase sulfurylase (moeB) mutation on Escherichia coli molybdoenzyme maturation. Biochemistry and Cell Biology 80:435-443.

Shah VK, and Brill WJ. 1980. Isolation of an iron-molybdenum cofactor from nitrogenase. Proceedings of the National Academy of Sciences of the United States of America 74:32493253.

Shah VK, Ugalde RA, Imperial J, and Brill WJ. 1984. Molybdenum in nitrogenase. Annual Review of Biochemistry 53:231-257 DOI 10.1146/annurev.bi.53.070184.001311.

Shi HW, Wang LY, Li XX, Liu XM, Hao TY, He XJ, and Chen SF. 2016. Genome-wide transcriptome profiling of nitrogen fixation in Paenibacillus sp. WLY78. BMC Microbiology 16:25 DOI 10.1186/s12866-016-0642-6.

Sperl GT, and Demoss JA. 1975. chlD gene function in molybdate activation of nitrate reductase. Journal of Bacteriology 122:1230-1238.

Taniguchi S, and Itagaki E. 1960. Nitrate reductase of nitrate respiration type from Escherichia coli.I. Solubilization and purification from the particulate system with molecular characterization as a metalloprotein. Biochimica et Biophysica Acta (BBA) - Bioenergetics 44:263-279.

Tweedie JW, and Segel IH. 1970. Specificity of transport processes for sulfur, selenium, and molybdenum anions by filamentous fungi. Biochimica et Biophysica Acta (BBA) Bioenergetics 196:95-106.

Villafane R, Bechhofer DH, Narayanan CS, and Dubnau D. 1987. Replication control genes of plasmid pE194. Journal of Bacteriology 169:4822-4829.

Wang LY, Zhang LH, Liu ZZ, Zhao DH, Liu XM, Zhang B, Xie JB, Hong YY, Li PF, Chen SF, Dixon R, and Li JL . 2013. A minimal nitrogen fixation gene cluster from Paenibacillus sp. WLY78 enables expression of active nitrogenase in Escherichia coli. PLoS Genetics 9:e1003865 DOI 10.1371/journal.pgen.1003865.

Welsh EA, Liberton M, Stockel J, Loh T, Elvitigala T, Wang C, Wollam A, Fulton RS, Clifton SW, Jacobs JM, Aurora R, Ghosh BK, Sherman LA, Smith RD, Wilson RK, and Pakrasi HB. 2008. The genome of Cyanothece 51142, a unicellular diazotrophic cyanobacterium important in the marine nitrogen cycle. Proceedings of the National Academy of Sciences of the United States of America 105:15094-15099 DOI 10.1073/pnas.0805418105.

Xie JB, Bai LQ, Wang LY, and Chen SF. 2012. Phylogeny of 16S rRNA and nifH genes and regulation of nitrogenase activity by oxygen and ammonium in the genus Paenibacillus. Mikrobiologiia 81:760-767.

Xie JB, Du ZL, Bai LQ, Tian CF, Zhang YZ, Xie JY, Wang TS, Liu XM, Chen X, Cheng Q, Chen SF, and Li JL. 2014. Comparative genomic analysis of N2-fixing and non-N2fixing Paenibacillus spp.: organization, evolution and expression of the nitrogen fixation 
535 genes. PLoS Genetics 10:e1004231 DOI 10.1371/journal.pgen.1004231.

536 Zhang W, Urban A, Mihara H, Leimkühler S, Kurihara T, and Esaki N. 2010. IscS

537 functions as a primary sulfur-donating enzyme by interacting specifically with MoeB and

$538 \quad$ MoaD in the biosynthesis of molybdopterin in Escherichia coli. Journal of Biological

$539 \quad$ Chemistry 285:2302-2308 DOI 10.1074/jbc.M109.082172

540 
Figure 1

Clusters of nitrogen-fixation related genes between P. polymyxa WLY78 and other nitrogen-fixing bacteria.

(A) P. polymyxa WLY78, (B) Frankia sp. EAN1pec, (C) Cyanothece sp. ATCC 51142, (D) Anabaena sp. PCC 7120 .

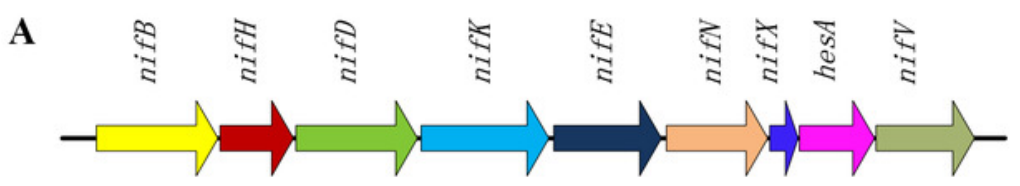

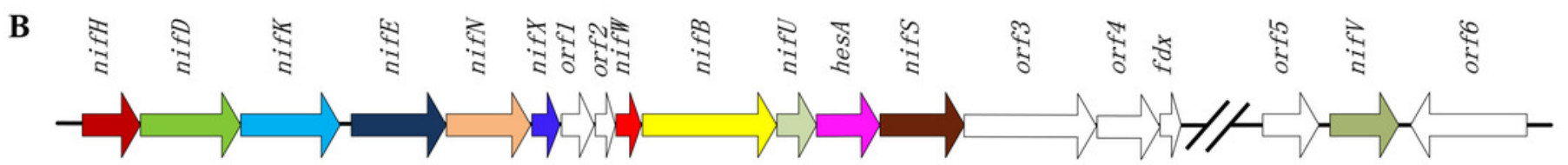

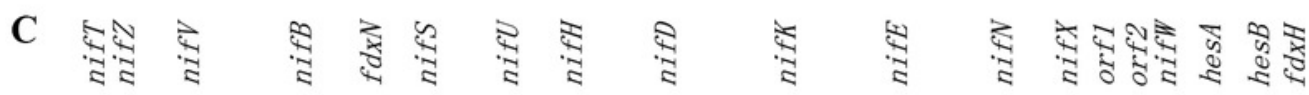

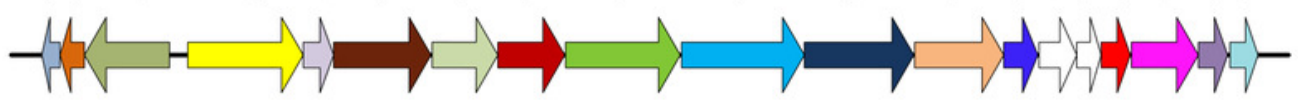

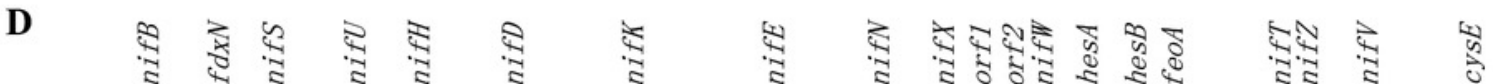

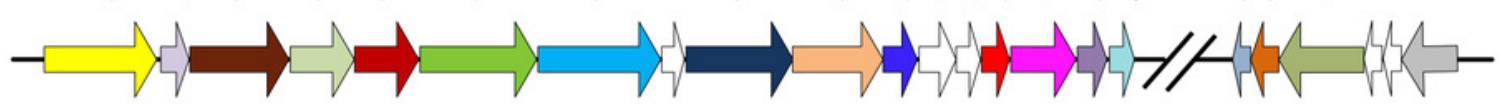




\section{Figure 2}

Relative nitrogenase activity of $P$. polymyxa WLY78, the $\triangle$ hesA mutant, the complemented strains $\Delta$ hesA (pHY300PLK-hesA) and $\Delta$ hesA (pHY300PLK-nifQ).

$\mathrm{X}$-axis indicates the concentration of molybdate added to the culture medium with $0.25 \mathrm{mM}$ sulfate as sulfur source. The nitrogenase activity of the $\Delta$ hesA mutant was used as a control. Date represent the mean $\pm S D(n=3)$. Single asterisk or double asterisks (* or **) indicate significant differences between control and other treatments determined by LSD at $P<0.05$ or $P<0.01$. 


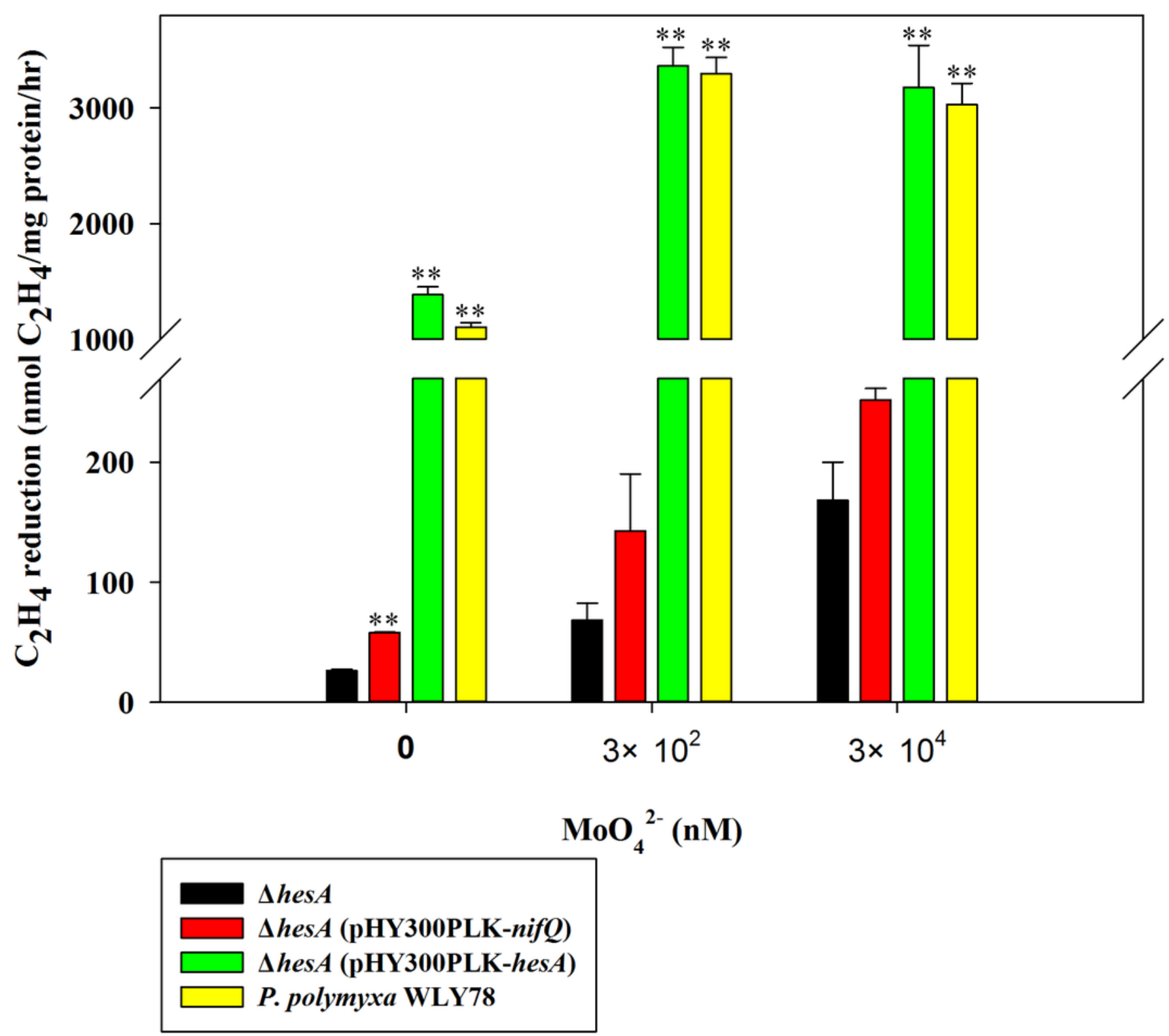


Figure 3

Effect of the molybdate concentration on nitrogenase activity $(A)$ and maximum growth (B) of P. polymyxa WLY78 and the $\triangle$ hesA mutant.

$\mathrm{X}$-axis indicates the concentration of molybdate added to the culture medium with $0.25 \mathrm{mM}$ sulfate as sulfur source. The maximum growth means culture absorbance after 48 hours under diazotrophic growth conditions. The nitrogenase activity of the $\Delta$ hesA mutant in the absence of added sodium molybdate was used as a control. Date represent the mean \pm SD $(n=3)$. Single asterisk or double asterisks (* or $* *)$ indicate significant differences between control and other treatments determined by LSD at $P<0.05$ or $P<0.01$.

A

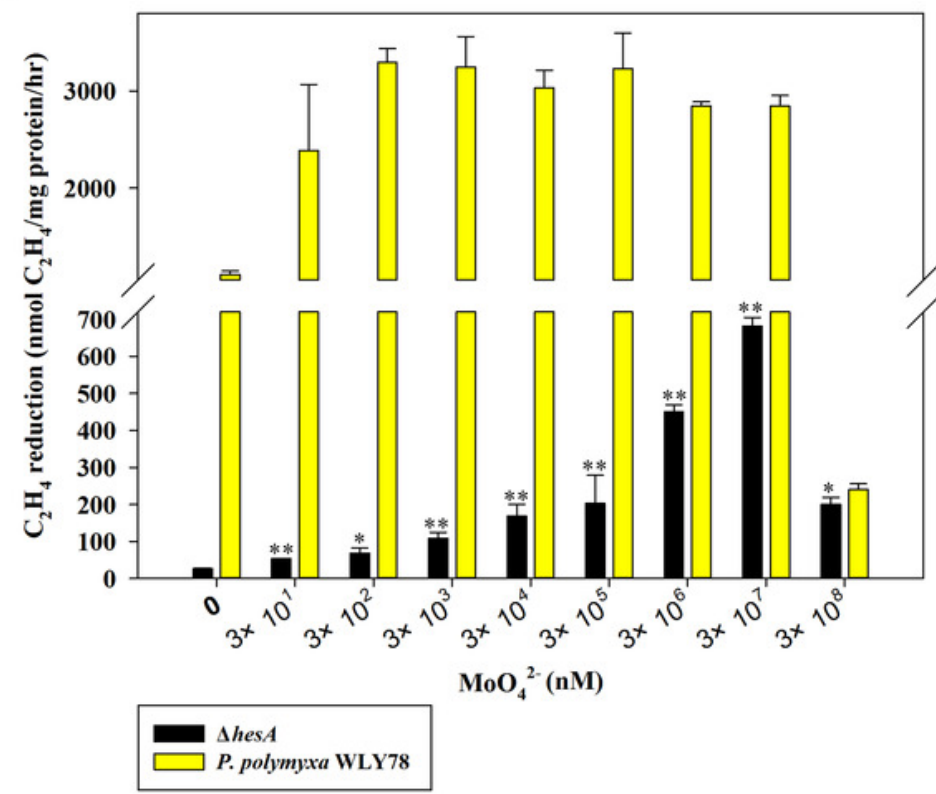

B

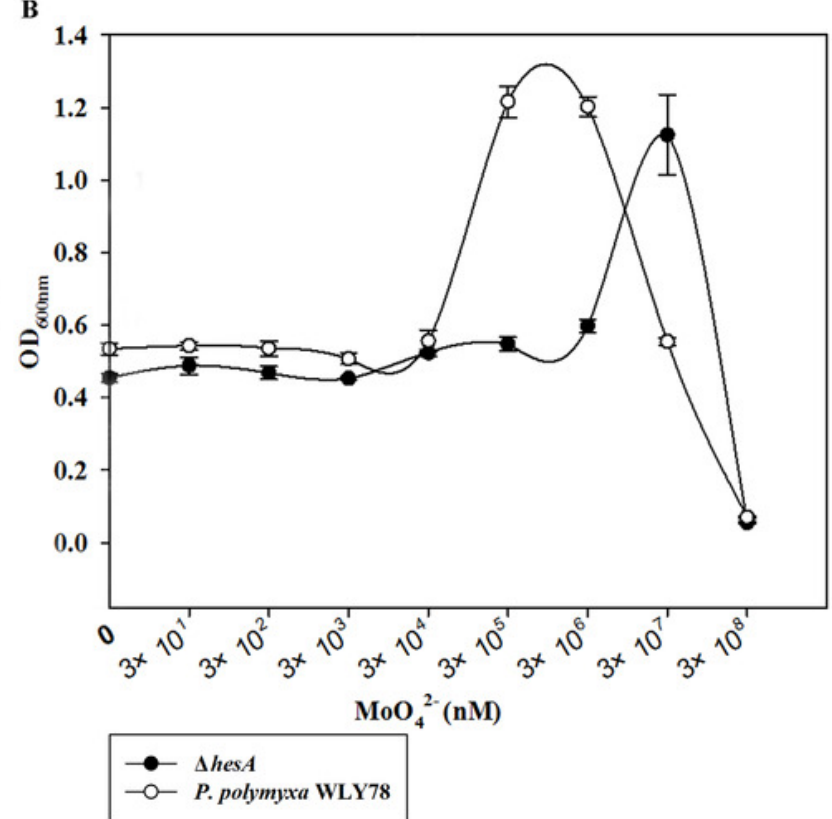




\section{Figure 4}

Effect of the sulfur sources on the nitrogenase activity of the $\Delta$ hesA mutant and $P$. polymyxa WLY78.

(A) Nitrogenase activity of $\Delta$ hesA with two sulfur sources. (B)Nitrogenase activity of $P$. polymyxa WLY78 with two sulfur sources. X-axis indicates the concentration of molybdate added to the culture medium with $0.25 \mathrm{mM}$ sulfate or $0.2 \mathrm{mM}$ cystine or the combination of sulfate and cystine as sulfur source. Date represent the mean \pm SD $(n=3)$. Single asterisk or double asterisks (* or **) indicate significant differences among different treatments determined by LSD at $P<0.05$ or $P<0.01$.

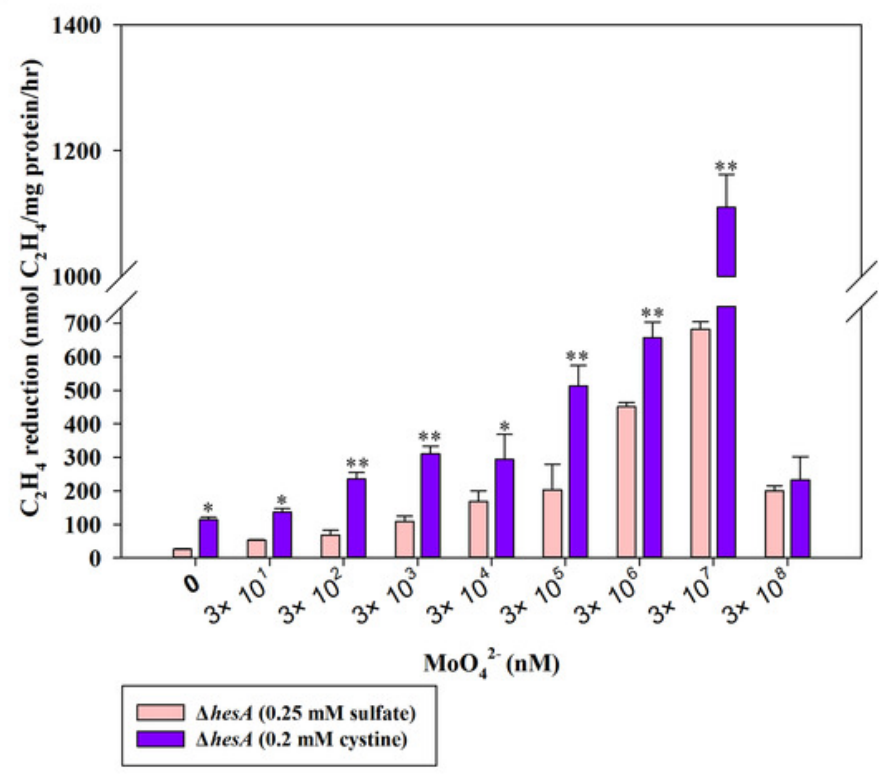

B

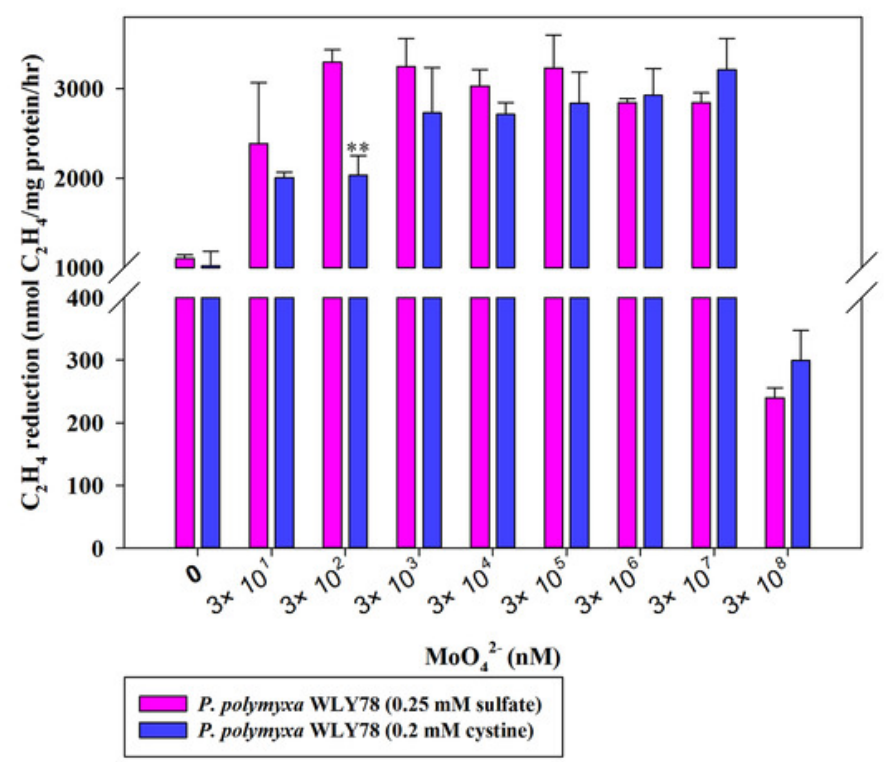




\section{Figure 5}

Effect of the different concentrations of cystine (A) or sulfate (B) on nitrogenase activity of $\triangle$ hesA, $P$. polymyxa WLY78 and the complemented strain $\triangle$ hesA (pHY300PLK-moeB).

(A) Nitrogenase activity of the strains with different cystine concentrations. (B) Nitrogenase activity of the strains with different sulfate concentrations. X-axis indicates the concentration of cystine or sulfate added to the culture medium with $30 \mathrm{mM}$ molybdate. The nitrogenase activity of the $\Delta$ hesA mutant was used as a control. Date represent the mean $\pm S D(n=3)$. Single asterisk or double asterisks (* or **) indicate significant differences between control and other treatments determined by LSD at $P<0.05$ or $P<0.01$.

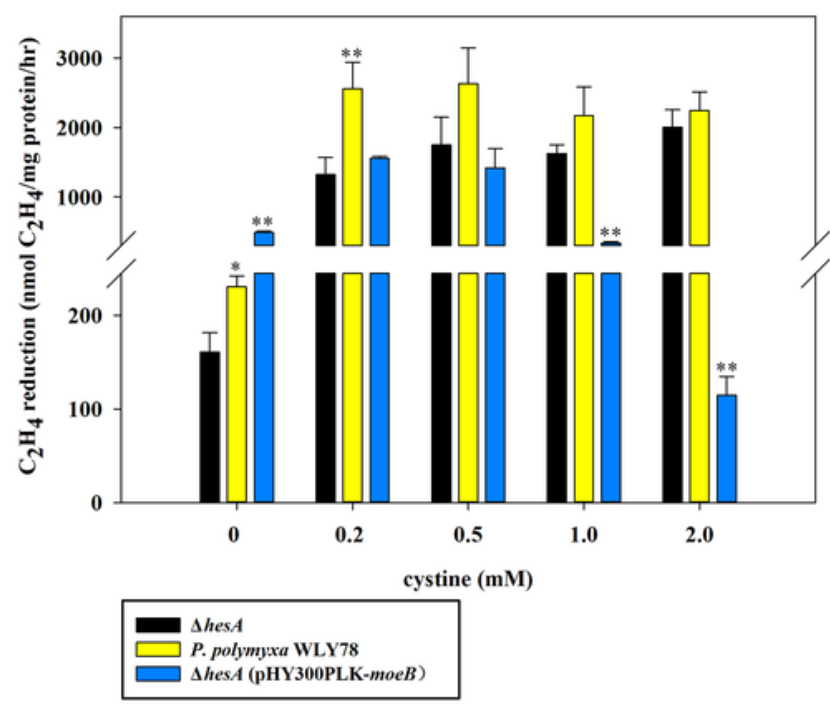

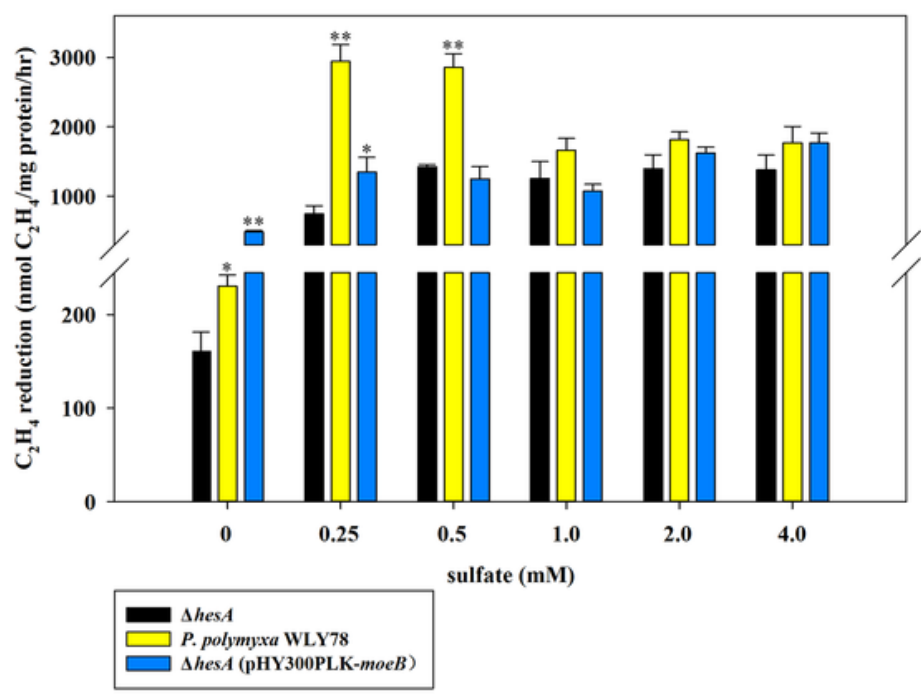




\section{Figure 6}

Effect of the molybdate concentration on nitrogenase activity of the recombinant $E$. coli 78-7, the hesA deletion strain (D-O) and the complemented strain D-O (pBluescript II SK (+)-hesA).

$\mathrm{X}$-axis indicates the concentration of molybdate added to the culture medium with $0.25 \mathrm{mM}$ sulfate as sulfur source. The nitrogenase activity of the D-O strain was used as a control. Date represent the mean $\pm S D(n=3)$. Single asterisk or double asterisks (* or $* *)$ indicate significant differences between control and other treatments determined by LSD at $P<0.05$ or $P<0.01$. 


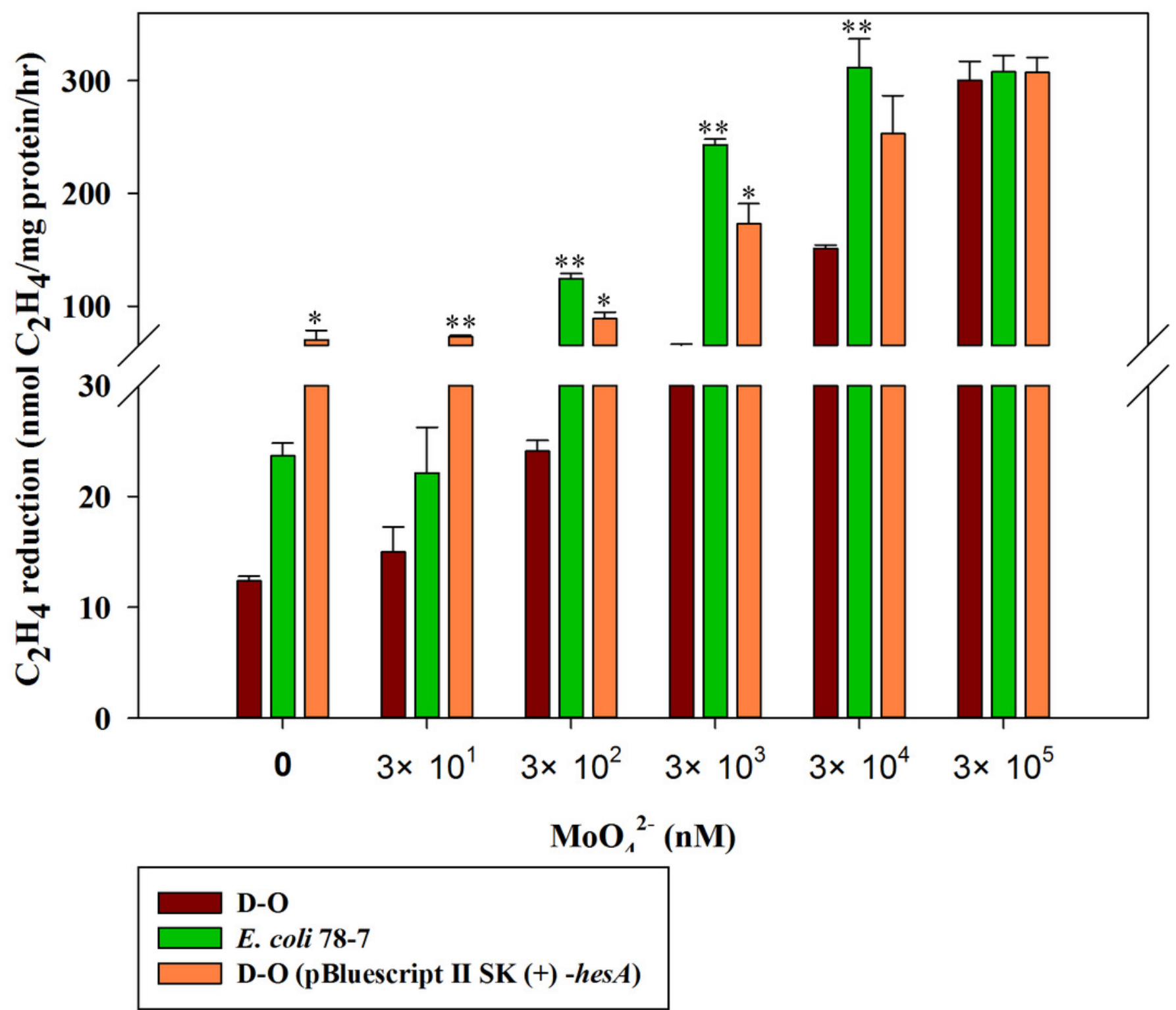




\section{Figure 7}

Effect of the cystine concentration on nitrogenase activity of the recombinant $E$. coli 78-7, the hesA deletion strain (D-O) and the complemented strain D-O (pBluescript II SK (+)-hesA).

$\mathrm{X}$-axis indicates the concentration of cystine added to the culture medium with $30 \mu \mathrm{M}$ molybdate. The nitrogenase activity of the D-O strain was used as a control. Date represent the mean $\pm S D(n=3)$. Single asterisk or double asterisks (* or **) indicate significant differences between control and other treatments determined by LSD at $P<0.05$ or $P<0.01$. 


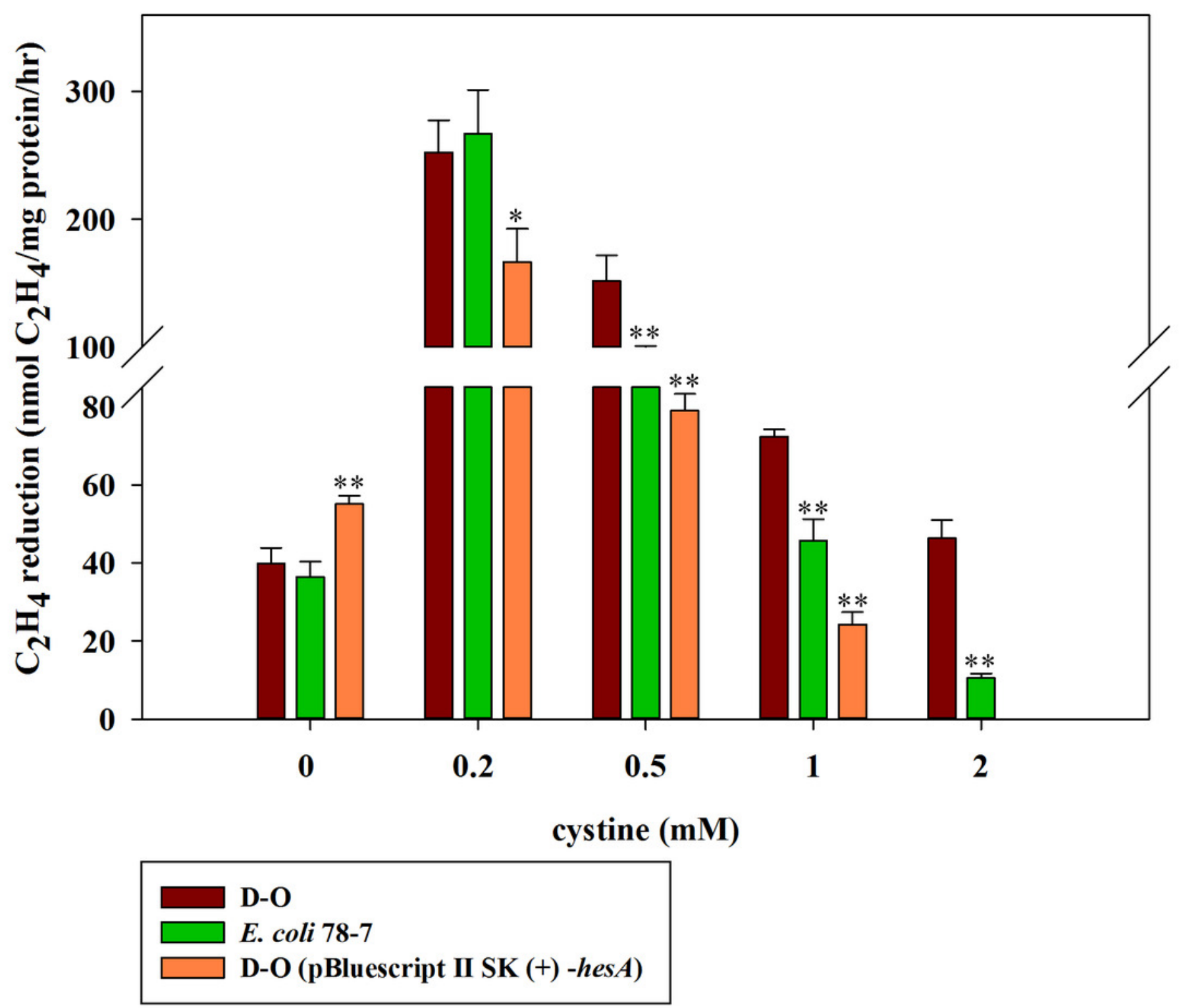

